\title{
Central Bank Transparency in Theory and Practice*
}

\author{
Maria Demertzis ${ }^{\dagger}$ \\ De Nederlandsche Bank Vanderbilt University and CEPR \\ Andrew Hughes Hallett
}

June 13, 2003

\begin{abstract}
We study the effects of Central Bank transparency on inflation and the output gap. We thus first identify a small analytical model which concludes that transparency affects the variability of inflation and output and not their average levels. Then we examine whether this conjecture holds empirically, employing the recently derived index of transparency by Eijffinger and Geraats. The empirical findings confirm that the averages are not affected by transparency. It does seem to explain however, about $50 \%$ of the variability in inflation. The relation between transparency and output volatility is less clear but appears to be positive rather than negative.
\end{abstract}

J.E.L Classification: E52, E58

Keywords: Central Bank, Economic and Political Transparency, Inflation and Output Gap performance

\footnotetext{
${ }^{*}$ Views expressed are our own and do not necessarily reflect those of the institutions we are affiliated with. We thank Peter Keus for helping us collect the data and Ard den Reijer for help with the detrending filters. We are grateful to seminar participants at De Nederlandsche Bank, the RES, 2003 at the University of Warwick, the 7th International Conference on Macroeconomic Theory and Policy in Crete, Lex Hoogduin, Peter van Els and Anders Vredin for comments and suggestions and Petra Geraats for discussions over the index. Any errors are naturally our own.

${ }^{\dagger}$ Contact details: m.demertzis@dnb.nl, Research Department, De Nederlandsche Bank, P.O. Box 98, 1000 AB, Amsterdam, the Netherlands, tel: +31 (0) 20524 2016, fax: +31 (0) 205242529 .

${ }^{\ddagger}$ a.hugheshallett@Vanderbilt.edu, Vanderbilt University, Box 35819 Station B, 415 Calhoun Hall, Nashville, Tennessee 37235, USA, tel: +1 (615) 322 8539, fax: +1 (615) 3438495.
} 


\section{Introduction}

Most economists agree that greater transparency in monetary policy is desirable because it allows the private sector to make better - that is, welfare improving - decisions, as well as better informed decisions (Blinder, 1998). But not all agree.

Some argue that incomplete transparency is optimal, as the effect on the Central Bank's reputation and its consequent ability to control inflation has to be balanced against the private sector's wish to see output, employment and prices stabilised (see for example Faust and Svensson, 2001 or Jensen, 2000). Others argue that certain restrictions on transparency are important for operational reasons. Once again the idea is to reinforce the Bank's credibility (see Eijffinger and Hoeberichts, 2002) and to separate 'the need to know' from 'the need to understand' (Issing, 1999).

In practice, many Central Banks have actually increased their transparency in recent years - using inflation forecasts, extensive explanations of the reasoning behind their decisions, and sometimes voting records on policy decisions or a discussion of the 'bias' in those decisions, to do so. Prominent examples are found in the Federal Reserve System in the US; but also in the Bank of England and the Central Banks of Canada, New Zealand and Sweden. Yet, on the basis of casual empiricism or circumstantial evidence, one cannot tell whether greater transparency has actually made any material difference to the policies chosen - or more exactly, to the impact and effectiveness of those policies. Nor is it possible to determine exactly what kinds of effects one should expect, in terms of average inflation, output performance and the stability of these indicators. Our purpose in this paper is therefore, to determine what effects a lack of Central Bank transparency should be expected to have on monetary policies and what impact that would have on the economy.

The main problem is that transparency has many different dimensions, and may mean different things to different people (Eijffinger and Geraats, 2002). Kuttner and Posen(2000) list a number of characteristics thought necessary for institutional transparency:

- a numerical goal for monetary policy,

- an inflation report, explaining the expected effects of changes in monetary policy

- an inflation forecast (plus assumptions) explaining why those changes were necessary and,

- a post-mortem evaluation of past policies and their achievements.

These attributes cover both the information content as well as the way in which that information has been used. That distinction is important, but is seldom made $^{1}$. This distinction itself relates directly to the potential for conflict between the ability to control and the need for transparency. As a result, many

\footnotetext{
${ }^{1}$ See the discussions in Friedman (1997) or Bomfin and Reinhart (2000).
} 
commentators reach opposite conclusions about the need for transparency. Kuttner and Posen (1999) argue that it enhances the Central Bank's ability to use discretionary policies, while Faust and Svensson (2002) argue the opposite (although for particular circumstances). In fact, both sets of authors agree that transparency will reduce the noise and the imprecision in the private sector's decision making. They only differ as to whether greater transparency would increase the ability of the Central Bank and private sector to make consistent decisions, or whether it would reduce the Central Bank's ability to control the private sector's natural tendency to avoid monetary discipline.

Since our purpose is to show what effects a lack of transparency may have on the economy, we have to allow for different degrees and different forms of imperfect transparency. A lack of transparency could be said to arise when the Central Bank has private information about the nature of shocks and the way in which policy affects the economy (Cukierman, 1992, 2000); or when the Central Bank has not stated its objectives clearly (Cukierman and Meltzer 1986); or when the public is uncertain about the preferences of the Central Bank (Nolan and Schaling, 1998, Muscatelli, 1998). To allow for each of these possibilities, we present imperfect transparency in two forms: imperfect political transparency about priorities and objectives, and imperfect economic transparency about the conditioning information, shocks, target values, etc. In either case, a lack of transparency introduces a disturbance which distorts the private sector' expectations for inflation. That provides an automatic link both to the incentive for the Central Bank to use its private information strategically, and to the private sector's desire to ensure accountability.

In this paper we examine these effects using a theoretical model of monetary policy, stripped down to its key components, and find that a lack of transparency does not alter the average inflation or output performance of an economy. But it does affect the stability of the economy, increasing both inflation variability and output volatility. Interestingly, both a lack of political transparency and a lack of economic stability affect the economy in the same way, so there is no possibility of distinguishing between them by their impact. Then, using a recently constructed index of Central Bank transparency due to Eijffinger and Geraats (2002), we test whether imperfect transparency has had the predicted effects in the main OECD countries. All our theoretical predictions are upheld, but that for output stability which appears to decrease with transparency instead of increase ${ }^{2}$.

The paper is organised as follows: Section 2 defines political and economic transparency and identifies the way they affect the moments of inflation and the output gap. Section 3 then employs the index of transparency by Eijffinger and Geraats (2002) to examine its empirical relevance. We look at two alternative groupings of this index and discuss the sensitivity of our results. Section 4 concludes.

\footnotetext{
${ }^{2}$ The empirical part of the exercise is very similar in nature to that underaken by Alesina and Summers (1993) when they explored how different indices of independece affect macroeconomic performance.
} 


\section{The effects of Greater Transparency}

We adopt a Rogoff (1985) type model of a conservative central banker in which the Central Bank (CB) has the following objective function:

$$
L=\frac{1}{2} E\left[\pi^{2}+b(y-k)^{2}\right]
$$

constrained by a simple Lucas supply function:

$$
y=\pi-\pi^{e}+\varepsilon
$$

where $y$ and $\pi$ are measured as deviations from their steady state paths. The model produces the following solutions for the policy variables in question:

$$
\begin{aligned}
\pi & =b k-\frac{b}{1+b} \varepsilon \\
\pi^{e} & =b k \\
y & =\frac{1}{1+b} \varepsilon
\end{aligned}
$$

We assume that there is only one player in the game (i.e. a single monetary authority and no fiscal policy ${ }^{3}$ ) and that there is no uncertainty in the transmission of policy effects. The way $k$ is defined in the literature is to note that some factors in the economy such as income taxation or unemployment insurance distort the labour-leisure decision and cause the market-determined level of employment (and output) to lie below their social optimum (Rogoff 1985). A parameter $k>0$ reflects the policy maker's desire to correct this distortion. There have however, been many objections as to whether having a central bank that sets out to impose an inflationary bias (i.e. $k \neq 0$ ) is a sensible specification to start with (Blinder 1997). We do not attempt to resolve that dispute here. Instead we simply note that $k$ may be positive or zero. That is to say, we include $k$ here because doubts about its exact value may constitute one important source of transparency problems in monetary policy.

In this paper we consider transparency problems which arise from two possible sources:

- misunderstandings about the true value of the preference parameters $b$, or

- misperceptions about the value of $k$ that the Central Bank can be expected to implement ${ }^{4}$.

\footnotetext{
${ }^{3}$ But see extensions to this model in which fiscal policy and hence a second player (the fiscal authority or the government) is incorporated, in Hughes Hallett and Viegi (2001) or Geraats (2002).

${ }^{4}$ Uncertainty in parameter $k$ also covers the case of uncertainty in the inflation target.
} 
We will identify the former with political transparency and the latter with an economic form of transparency, in line with Hughes Hallett and Viegi $(2001)^{5}$. We then examine how varying the degree of transparency, in either form, affects the ability to achieve lower inflation and more stable output.

\subsection{Imperfect Political Transparency: the public is uncer- tain about the true value of $b$}

To define full transparency, we start from a general specification in which the Central Bank attaches explicit weights to both its objectives. It is important to define transparency in its most general form and only then impose normalisation restrictions, in order to account for all relevant information. We therefore consider a Central Bank which assigns positive numbers, $a$ and $b$, as weights or priorities to the targets in its objective function:

$$
L=\frac{1}{2} E\left[a \pi^{2}+b(y-k)^{2}\right]
$$

But in identifying a loss function what we are actually interested in is not the value of each of the parameters $a$ and $b$ per se, but the relative weight attached to the two objectives $\frac{b}{a}$, and the Marginal Rate of Substitution between them: $\frac{b}{a} \frac{\Delta \pi}{\Delta y}$. The issue of transparency arises when the public's perception about the bank's preferences, for example on output $(\beta)$, differs from the values that the bank itself actually considers $(b)$. We define this discrepancy as $\beta=b+\eta$ where $\eta$ is a random error with $E(\eta)=0$ and $V(\eta)=\sigma_{\eta}^{2}$. This implies that the public is correct on average, but may be mistaken when making guesses about the central bank preferences in individual cases or at certain points in time. But uncertainty about $b$ implies that the relative importance that the Central Bank attaches to controlling inflation is also uncertain in the public's perception. To show this, we rescale the sum of two parameters to equal a constant, say $a+b=1$. This is a simplifying assumption (see Geraats 2002) which helps define uncertainty in $a$ in terms of $\eta$ as well, i.e. $\alpha=a-\eta$. Similarly to above, $E(\alpha)=a$. However, this is not sufficient in itself to define transparency. Full transparency would also require the ratio of the two parameters as perceived by the public, to equal the ratio of the true values, on average. This is not automatically implied by the assumptions made so far, since the expectation of a ratio is not the ratio of the expectations. In fact, the perceived relative weights are :

$$
\frac{\beta}{\alpha}=\frac{b+\eta}{a-\eta}
$$

and the possibility of full transparency requires that $E\left(\frac{\beta}{\alpha}\right)=\frac{b}{a}$. We can rewrite (3) as:

\footnotetext{
${ }^{5} \mathrm{~A}$ similar distinction between economic and political transparency is made by Eijffinger and Hoeberichts (2002).
} 


$$
\frac{\beta}{\alpha}=\frac{b+\eta}{a-\eta}=\frac{b}{a}+\xi
$$

where $\xi=\frac{(a+b) \eta}{a(a-\eta)}$, and hence

$$
E(\xi)=E\left[\frac{(a+b) \eta}{a(a-\eta)}\right]=\frac{(a+b) \bar{\eta}}{a(a-\bar{\eta})}-\frac{(-a)(a+b) \sigma_{\eta}^{2}}{a^{2}(a-\bar{\eta})^{2}}+\frac{a^{2}(a+b) \bar{\eta}}{a^{3}(a-\bar{\eta})^{3}} \sigma_{\eta}^{2}
$$

We can now see that the assumption $E(\eta)=0$ is not sufficient for full transparency. For the Central Bank to be capable of delivering full transparency, at least potentially, $E(\xi)=0$ is also required. Imposing $E(\eta)=0$ alone, implies that

$$
E(\xi)=\frac{(a+b) \sigma_{\eta}^{2}}{a^{3}}
$$

and hence that $E(\beta / \alpha) \neq b / a$. The Central Bank cannot therefore, deliver full transparency unless it provides the private sector with full information (i.e. $\left.\sigma_{\eta}^{2}=0\right)$ at the same time. Consequently, we define full political transparency as follows:

Definition 1: Full political transparency occurs if conditions $E(\eta)=0$ and $\sigma_{\eta}^{2}=0$, both hold.

Note that the objective function we will be using assumes $a=1^{6}$. This is a convenient simplification and does not change any of the qualitative results we present since the conditions for transparency remain the same. Following this definition, public perceptions and Central Bank preferences are related through $\beta=b+\eta$ where $\eta$ has the properties defined above. This implies that the public will on average anticipate the correct preference parameter, i.e. $E(\beta)=b$. But for full transparency to hold, we need $\sigma_{\eta}^{2}=0$ as well. The private sector therefore, expects the CB to implement:

$$
\begin{aligned}
\pi & =\beta k-\frac{\beta}{1+\beta} \varepsilon \quad \text { with } \\
\pi^{e} & =\beta k
\end{aligned}
$$

Given this definition and the public's perception, we now have:

Proposition 1 If the $C B$ can correctly anticipate what the public thinks, then an increase in political transparency reduces the variability of inflation and output but it does not affect their average levels.

\footnotetext{
${ }^{6}$ And by implication also $\alpha=1$. This is in fact the normalisation adopted in most studies of the transparency problem: see Cukierman (2000), Sibert (2002) or Muscatelli (1998).
} 
Proof: The CB optimises the following:

$$
\min _{\pi} L=\frac{1}{2} E\left[\pi^{2}+b(\pi-\beta k+\varepsilon-k)^{2}\right]
$$

leading to the following equilibrium inflation path:

$$
\pi^{*}=\frac{b(1+\beta) k}{1+b}-\frac{b}{1+b} \varepsilon
$$

Note that $E\left(\pi^{*}\right)=b k=E\left(\pi^{e}\right)$ because $E(\beta)=b$, so that the public's expectations are right on average. In that sense, this is still a rational expectations (RE) solution. Moreover, the variance of inflation is:

$$
V\left(\pi^{*}\right)=E\left[\pi^{*}-E\left(\pi^{*}\right)\right]^{2}=\left(\frac{b}{1+b}\right)^{2}\left(k^{2} \sigma_{\eta}^{2}+\sigma_{\varepsilon}^{2}\right)
$$

assuming that $E(\eta, \varepsilon)=0$. The variance of inflation is therefore, a function of the lack of transparency perceived by the public. Indeed as $\sigma_{\eta}^{2}$ increases (and transparency falls), then the variance of inflation increases as well:

$$
\frac{\partial V\left(\pi^{*}\right)}{\partial \sigma_{\eta}^{2}}=\left(\frac{b}{1+b}\right)^{2} k^{2}>0
$$

unless $b=0$ or $k=0^{7}$. But the average level of inflation is not a function of the variance of $\eta$ and therefore remains unaffected:

$$
\frac{\partial E\left(\pi^{*}\right)}{\partial \sigma_{\eta}^{2}}=0
$$

even if $b \neq 0$ or $k \neq 0$. We can likewise examine what happens to output. In equilibrium, output is equal to:

$$
y^{*}=\frac{\varepsilon-\eta k}{1+b}
$$

But this implies that $E\left(y^{*}\right)=0$ and that

$$
V\left(y^{*}\right)=\frac{\sigma_{\varepsilon}^{2}+k^{2} \sigma_{\eta}^{2}}{(1+b)^{2}}
$$

if $E(\eta, \varepsilon)=0$. Again this implies that the average level of equilibrium output remains unaffected by changes in the degree of transparency but the variance of output is reduced as political transparency increases:

$$
\frac{\partial V\left(y^{*}\right)}{\partial \sigma_{\eta}^{2}}=\frac{k^{2}}{(1+b)^{2}}>0
$$

${ }^{7}$ The intution behind this result is that if $b=0$ or $k=0$, there is effectively only one target and one instrument and as in Tinbergen's theory of economic policy, that target can be reached exactly on average. Consequently there is no issue of transparency to be analysed in this case - in contrast to the cases represented by (6), (7) and (8). 
Finally, comparing our results in (9) and (13) we also see that:

$$
\frac{\partial V\left(y^{*}\right)}{\partial \sigma_{\eta}^{2}}>\frac{\partial V\left(\pi^{*}\right)}{\partial \sigma_{\eta}^{2}}
$$

if the $\mathrm{CB}$ is conservative (i.e. if $b<1^{8}$ ). Hence a lack of transparency is more damaging to output stability than it is to inflation variability - and vice versa if $b>1$ - the average values of both being unaffected. We will see below that a lack of economic transparency will deliver exactly the same result, and in the same ratio.

\subsection{Imperfect Economic Transparency: The Public is Un- certain about parameter $k$}

We consider next a different form of transparency, this time relating to the public being uncertain about the value of $k$ that the CB targets $^{9}$ (the control errors approach by Cukierman, 2000, Geraats, 2002, Jensen, 2000, Faust-Svensson, 2001). We identify this with imperfect economic transparency. Suppose the CB targets $k$ but the public anticipates $c=k+v$, where $v$ is an error with $E(v)=0$ and $V(v)=\sigma_{v}^{2}$. As a consequence, $E(c)=k$. Then

Definition 2: Full economic transparency occurs when conditions $E(v)=0$ and $\sigma_{v}^{2}=0$ both hold.

The public will therefore, expect the CB to implement:

$$
\begin{aligned}
\pi & =b c-\frac{b}{1+b} \varepsilon \\
\pi^{e} & =b c
\end{aligned}
$$

This time transparency is indexed by the variability of $v$ and full economic transparency is identified with $\sigma_{v}^{2}=0$. Notice that $k$ now contains all the conditioning information needed from outside the problem: on exogenous and random variables, on decisions made by other players and the target values imposed by the policy makers themselves.

Proposition 2 If there is uncertainty about the value of output the CB targets, then an increase in economic transparency reduces the variability of inflation and output. The levels of inflation and output remain, on average, unaffected.

Proof: As the CB knows what the public's perceptions are, it will try to optimise the following loss function:

$$
\min _{\pi} L=\frac{1}{2} E\left[\pi^{2}+b(\pi-b c+\varepsilon-k)^{2}\right]
$$

${ }^{8}$ Conservative with respect to inflation so that $b<a=1$.

${ }^{9}$ In this section $b$ is known to the public without uncertainty. 
where $\pi^{e}=b c$. This results in an equilibrium level of inflation of

$$
\pi^{*}=\frac{b(b c+k)}{1+b}-\frac{b}{1+b} \varepsilon
$$

Since $E(c)=k$, this implies that $E\left(\pi^{*}\right)=b k$. Hence the private sector is again correct on average and the solution is a Rational Expectations equilibrium since $E\left(\pi^{*}\right)=E\left(\pi^{e}\right)=b k$. We can therefore write the variance of inflation as:

$$
V\left(\pi^{*}\right)=E\left[\pi^{*}-E\left(\pi^{*}\right)\right]^{2}=\left(\frac{b}{1+b}\right)^{2}\left(b^{2} \sigma_{v}^{2}+\sigma_{\varepsilon}^{2}\right)
$$

Thus the variance of inflation is increasing in the variance of $v$, and consequently decreasing in transparency:

$$
\frac{\partial V\left(\pi^{*}\right)}{\partial \sigma_{v}^{2}}=\left(\frac{b}{1+b}\right)^{2} b^{2}>0
$$

The results for output can be derived in a similar way. The public forms expectations for inflation, $\pi^{e}=b c$. In equilibrium therefore, output is equal to:

$$
y^{*}=\frac{\varepsilon-b v}{1+b}
$$

It is easy to see that $E\left(y^{*}\right)=0$ and therefore, $\frac{\partial E\left(y^{*}\right)}{\partial \sigma_{v}^{2}}=0$. In addition the variance of equilibrium output is given by:

$$
V\left(y^{*}\right)=\frac{\sigma_{\varepsilon}^{2}+b^{2} \sigma_{v}^{2}}{(1+b)^{2}}
$$

assuming $\varepsilon$ and $v$ to be uncorrelated. Hence the variance of output once again decreases with economic transparency.

$$
\frac{\partial V\left(y^{*}\right)}{\partial \sigma_{v}^{2}}=\frac{b^{2}}{1+b^{2}}>0
$$

Similarly, $\frac{\partial V\left(y^{*}\right)}{\partial \sigma_{v}^{2}}>\frac{\partial V\left(\pi^{*}\right)}{\partial \sigma_{v}^{2}}$ if the CB is conservative $(b<1)$. So, just as with a lack of political transparency, a lack of economic transparency is more damaging to output stability than to inflation variability in a conservative regime. At this point there is no analytic distinction between the impacts of the two different types of incomplete transparency.

\subsection{Summary}

- A lack of transparency, whether of the political or economic type, implies no bias in average inflation or average output levels. Private sector expectations will be correct and the average inflation/output outcomes will be the same as they would be under full transparency with the same parameter values. In that respect, it is not a problem that the policy makers or private sector need be concerned about. 
- In the short term however, a private sector that believed the Central Bank to be more conservative than it actually is $(\beta<b$ and/or $c<k)$, might temporarily experience lower inflation and higher output than otherwise. Conversely, inflation would be temporarily higher and output lower if it believed the $\mathrm{CB}$ to be more liberal.

- A lack of transparency does affect the variability of the outcomes however. Incomplete transparency makes both inflation and output more variable but it affects output variability more than it does inflation. Conversely, greater transparency produces more stable output and inflation outcomes, but the larger gains will be in output stability. These results hold equally for both political and economic transparency under a conservative central banker $(b<1)$. But the greater sensitivity of output volatility would be reversed under a liberal Central Bank.

- Since the average outcomes are unaffected, and the ratio of $V\left(y^{*}\right)$ to $V\left(\pi^{*}\right)$ is the same under a lack of political and economic transparency, there are no testable differences in the outcomes from this model. That means that these two cases can only be distinguished in the data with prior information: e.g. from survey information - such as in the index we use in section 3 below - or if it is known that $\sigma_{\eta}^{2}$ is small relative to $\sigma_{v}^{2}$. But if either the zero bias or the increasing stability results in (5), (7), (8) or (9) are violated - then neither form of transparency holds and we must look for other explanations of the impact of asymmetric information on monetary policy making; and for any ineffectiveness in those policies which may result.

\section{$3 \quad$ An Index of Transparency}

\subsection{The Index and its components}

To test the significance of our results in practice, we use an index of transparency recently constructed by Eijffinger and Geraats, 2002 (henceforth E\&G). The index is compiled for nine major central banks and is based on information disclosed by the banks themselves. Furthermore, it distinguishes between various aspects of transparency, based on the ways in which they affect monetary policy. The E\&G index is defined by the following components of transparency: 
Table 1: Transparency Components, E\&G Index

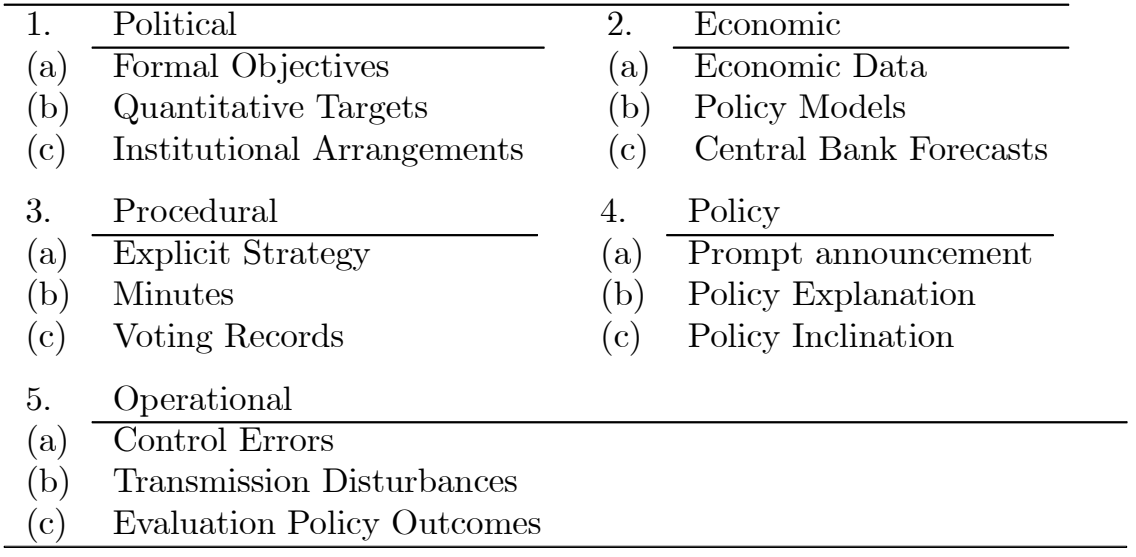

Table 2 below presents the scores obtained for the individual banks, in decreasing order of total transparency:

Table 2 : The E\&G Index of Central Bank Transparency (and its components)

\begin{tabular}{|c|c|c|c|c|c|c|}
\hline & Political & Economic & Procedural & Policy & Operational & Total \\
\hline New Zealand & 3 & 2.5 & 3 & 3 & 2 & 13.5 \\
\hline UK & 3 & 2.5 & 3 & 1.5 & 2.5 & 12.5 \\
\hline Sweden & 3 & 2 & 2 & 2 & 3 & 12 \\
\hline Canada & 3 & 2.5 & 1 & 2 & 2 & 10.5 \\
\hline $\mathrm{ECB}$ & 3 & 2.5 & 1 & 1.5 & 2 & 10 \\
\hline US & 1 & 2.5 & 2 & 3 & 1.5 & 10 \\
\hline Australia & 3 & 1 & 1 & 1.5 & 1.5 & 8 \\
\hline Japan & 1.5 & 1.5 & 2 & 1.5 & 1.5 & 8 \\
\hline Switzerland & 2.5 & 1.5 & 1 & 2 & 0.5 & 7.5 \\
\hline
\end{tabular}

The last column is the arithmetic sum of the individual columns and reflects a measure of total transparency. Interestingly, the ordering of banks would change if one were to look at the specific components separately. For example, New Zealand's political, procedural and policy transparency is not matched by an equivalent degree of clarity about her actual monetary policy operations. Similarly, Australia's political transparency does not translate into an equal degree of economic and procedural transparency. At the other end of the scale, the US transparency on economic and policy matters is not matched by transparency over political priorities. Although these variations may be fairly small overall, they are bound to affect the results in some way. We attempt to account for that in what follows by showing that essentially the same results hold under alternative aggregations of the transparency attributes.

Two questions however, remain. First, what is the empirical relevance of such an index, in terms of whether the degree of transparency affects the main indicators 
of macroeconomic performance? Second, what is the relative importance of the individual components? In order to identify its empirical relevance, we regress the transparency index on, first, the average inflation rate and its standard deviation over a specified period for the countries in question; and second, on the average output deviation from trend and its standard deviation for the same sample period and same group of countries. Naturally, the choice of period considered is consistent with the institutional set-up reflected in the index. Since this varies from country to county, the sample period also differs for each of the nine countries. Appendix B includes a full description of the data used for each country and justifies the choice of sample used. Figures 1-4 show the cross plots of the average and standard deviation of inflation and the output gap against the index of transparency and the line of best fit given by the following model:

$$
Y_{i}=\phi+\lambda_{i j} X_{j}
$$

where

$$
\begin{array}{lll}
i: \begin{array}{l}
\text { average inflation, } \\
\text { SD of inflation, } \\
\text { average output gap, } \\
\text { SD of output gap }
\end{array} & j: \quad \begin{array}{l}
\text { indices of political, economic, } \\
\text { procedural, policy, } \\
\text { operational and total transparency }
\end{array} \\
\end{array}
$$

Parameter $\lambda_{i j}$ stands for the impact of index $j$ on variable $i$. The regressions are implemented in univariate terms in order to examine the effect of the index in question on the moment of a given macro variable. The figures included report these regressions, their $R^{2}$ and the $t$ statistic on the significance of the slope parameter $\lambda_{i j}$.

\subsection{Empirical Results}

- Our empirical results confirm that there is no statistically significant correlation between the index of Central Bank transparency and average inflation rates, or the average output deviation from trend (and hence output growth), for our sample of nine OECD Central Banks. This confirms the first of the analytical predictions derived from our theoretical model. Figures 1 and 3 show the relevant regression results, where the index of transparency is the independent variable and the t-ratio reflects the significance of the slope parameter (critical value: $t_{(8), 95 \%}=2.3$ ).

- Looking at the components of transparency however, the picture is slightly different. We still fail to identify any significant relationships between the variables and the indices. But it is interesting to see that not all components affect the average level of inflation and output in the same direction. Perhaps predictably, greater political, economic and policy making transparency seem to go with greater inflation expectations in the markets. The same holds for output gaps but with reference to political and operational transparency only. It is worth investigating whether alternative combinations of the different aspects of transparency would produce the 
same results, even if the overall effects appear to be less significant at the aggregate level than at the component level.

- Having covered the results for average inflation and output, it is the variances of inflation and output that are really affected by the degree of Central Bank transparency. This can be seen in figures 2 and 4 which show how increasing transparency stabilises inflation but appears to increase output variability. The former is exactly as predicted by our theoretical analysis; and this result is statistically significant according to the slope coefficient's t-ratio $(=3.06)$. The latter however, is the opposite of what our theoretical analysis predicted, although it does not appear to be statistically significant except in so far as operational transparency is concerned. Hence, these empirical results could be consistent with our theoretical model if the output volatility relationship is genuinely insignificant and biased to the wrong sign by small sample fluctuations; or if the lack of transparency refers to the degree of target conservatism $k$, rather than weight conservatism, $b$; or if the transparency index is actually picking up some other aspect of Central Bank behaviour - for example differing degrees of independence or differing degrees of uncertainty about how Central Banks actually formalise and pursue their own targets. Obviously, to analyse that question lies beyond the scope of this paper - if only because it may relate to a different type of transparency problem.

- One of the most interesting features of the index is that it allows us to look at the empirical relevance of each of the sub-components individually. The results attained show that it is the economic and operational components of transparency that matter the most for the variability of inflation. The former refers to the transmission mechanism: the anticipated changes in the economy which are accounted for by changes in the instrument. The latter refers to the unpredictable part of the economy, not accounted for by current policy changes. Their significance demonstrates that the private sector would appreciate some discussion over these two because they provide the basis for evaluating the Bank's performance. Interestingly, institutional features like independence or the existence of a quantitative target per se, summarised as the political component of transparency, appear to have a less significant impact. Hence, the mere fact of granting independence, for example, is not sufficient for transparency. What is more important is the implications of any given institutional set-up: for example how it changes the central bank's ability to evaluate their own policies or to explain their strategy or even publish forecasts. Adopting transparency may therefore be necessary. But it is the Bank's powers of communication, given that transparency, which is the sufficient condition for helping the public understand the intentions of the monetary authorities. In as far as output variability is concerned, operational transparency is the only component that seems to have a significant impact (at the $90 \%$ significance level), but then in the wrong direction in that it increases the deviations from trend. The private sector therefore, seems to understand 
that greater clarity in the intentions of the Central Bank will entail some costs in terms of output gaps.

\subsection{Alternative Weighing Schemes}

In this section, we use the E\&G index again but regroup its components in order to produce an index for economic and political transparency which corresponds to the theoretical model described above. We re-group the components described in Table 1 as follows: Political Transparency is now defined as the sum of 1a, 1c, 3a, 3b, 3c, 4a, 4b and 4c and Economic Transparency is now defined as the sum of $2 \mathrm{a}, 2 \mathrm{~b}, 2 \mathrm{c}, 5 \mathrm{a}, 5 \mathrm{~b}, 5 \mathrm{c}$ and $1 \mathrm{~b}$. Category $1 \mathrm{~b}$, which captures the existence of a quantitative target, is in our view better placed under the economic definition of transparency. In practice it actually makes very little difference which way the scores under $1 \mathrm{~b}$ are actually allocated. Table 3 below shows how the different Central Banks score under the new transparency groupings.

Table 3: Alternative Index of Transparency

\begin{tabular}{|c|c|c|c|}
\hline & Political & Economic & Total \\
\hline New Zealand & 8 & 5.5 & 13.5 \\
\hline UK & 6.5 & 6 & 12.5 \\
\hline Sweden & 6 & 6 & 12 \\
\hline Canada & 5 & 5.5 & 10.5 \\
\hline ECB & 4.5 & 5.5 & 10 \\
\hline US & 6 & 4 & 10 \\
\hline Australia & 4.5 & 3.5 & 8 \\
\hline Japan & 5 & 3 & 8 \\
\hline Switzerland & 4.5 & 3 & 7.5 \\
\hline
\end{tabular}

We now repeat the same regression exercise in order to establish the empirical properties of our new indices of economic and political transparency. The results can be summarised as follows (figures 5-6):

- The average inflation and inflation variability results match our previous findings, for the new indices of political and economic transparency. The mild trends in the average inflation results are clearly insignificant and anyway mutually offsetting. They are likely to be the result of small sample problems therefore. But the inflation stability results are significant and of the right sign in both cases. These results are exactly as our theoretical model predicts, (figure 5).

- The average output and output stability results are again as before. There is essentially no trend in the average output results at all, as anticipated. This result holds as before, for both types of transparency. However, the output variability results continue to show the wrong sign and more strongly now for economic transparency than for political transparency. However both relationships remain statistically insignificant, (figure 6). 


\subsection{Sensitivity}

We provide a detailed sensitivity analysis of the results derived in Appendix B and only summarise here the shortcomings of the analysis undertaken.

- Clearly, the limitations of the data cannot be emphasised often enough. The results of this exercise can therefore only be seen as correlations between variables rather than robust causal relations. There are only 9 data points which implies that the removal or addition of one observation can (and does) alter the results (See Appendix B for examples of this). We have therefore been very reluctant to remove outliers (e.g. Japan and/or Switzerland) in order to try and capture as much information as possible out of such a set. As explained in the appendix, (and shown in figures 7 and 8) the significant results attained remain robust to changes in the countries included, pointing in the direction of a substantive relationship. But elsewhere, we are not able to tell whether insignificant results are due to the lack of data or to a lack of correlation.

- As explained above, the mean and variance for inflation and output deviations from trend are regressed against the indices of transparency. The period chosen to calculate the means and standard deviations is crucial empirically but naturally, also theoretically. It is thus important to consider the average and variance of that period which is consistent with the institutional set-up captured by the E\&G index. The choice of period is based on a number of papers written by the Central Banks themselves, in which they explain their latest institutional changes and their precise timing (see Appendix B). At the same time it is important to try to keep the period as long as possible in order to include as much information in the data set as possible. We have experimented with the choice of period for the Bank of England and the ECB. The relevant timing for the UK is from the beginning of 1998 onwards. We find that if the moments of the UK inflation and output gap series considered refer to the whole of the 1990s instead, the overall relationship between the variables and transparency weakens, (see figure 9). In that sense, the increase in transparency at the Bank of England has clearly had desirable effects. The same experiment for the Euro area does not make an appreciable difference in the results and is therefore not reported.

- The results referring to deviations of output from trend, depend on the detrending method used to derive potential output. The results discussed so far rely entirely on the statistical filters by Hodrick and Prescott, 1997 (HP). There are a number of alternative filtering procedures however, and we experiment with the one based on the Christiano and Fitzgerald, 1999 contribution $(\mathrm{CF})$. The choice of filter does make some difference - in particularly with respect to the average deviations from trend and (less so) for the variance of output. We compare figures 3,4 and 5, to figures 10, 11 and 12 respectively. This comparison provides further evidence 
in support of our theoretical model, that transparency is related to the variance of the output gap, rather than to its average level. (see Appendix B for a detailed discussion).

\section{Commentary and Qualifications}

\subsection{Transparency and the Direction of Causality}

The set-up in (16) assumes that it is transparency that affects macroeconomic performance. It is oftern argued however, that low inflation countries have central banks that are much keener to be transparent, while central banks that are faced with high inflationary pressures are reluctant to be transparent. This in turn, implies that (16) may need to be written the opposite way, with transparency being the result of performance. The implication is that the t-statistic presented may be an unreliable measure of statistical strength. But since it is difficult to test for causality given the very limited number of data points, we examine the significance of the correlation coefficients between the variables in question. This does not resolve the issue of which way the causality runs, but it does help verify the reliability of the results presented so far. We do this by applying Fisher's transformation:

$$
z=0.5 \ln \left(\frac{1+\rho}{1-\rho}\right)
$$

This statistic is approximately normally distributed, with mean zero and standard deviation $\sigma=(n-3)^{-\frac{1}{2}}$, where $n$ is the sample size, in our case 9. The hypothesis tested is $H_{0}: \quad \rho=0$ against the alternative $H_{1}: \quad \rho \neq 0$. A two-tail test requires

$$
\begin{aligned}
& |\rho|>0.66 \\
& |\rho|>0.584
\end{aligned}
$$

at the $5 \%$ and $10 \%$ significance levels, respectively. Since, in the univariate equation framework $R^{2}=\rho^{2}$, the transformation is equivalent to testing for $R^{2}>0.44$ and $R^{2}>0.34$, respectively. Comparing the $R^{2}$ statistic in Figures 1-12 to these two critical values, gives identical results. The strength of the relationships described above therefore, holds irrespective of the direction of causality one chooses to believe. Nevertheless, a policy maker directly interested in knowing how much transparency can affect macroeconomic performance would be interested in the elasticities (and their significance) implied by (16).

\subsection{Transparency and Independence}

The disappointing result in this analysis is that we have failed to find a negative relationship between the E\&G index of transparency and output variability. All the other theoretical predictions have been borne out by these data on 
transparency. One explanation of this failure, but not the only one, is that this index of transparency conflates independence with transparency in a world where one might expect independence and output volatility to be positively related. The reasons for suspecting a positive relation between transparency and independence are:

1. Political and economic independence have been recognised, over the past 15 years, as the crucial properties for good central bank performance. But as independence has increased in the OECD and European economies, so has the need for political legitimacy and public accountability led to demands for greater transparency (Blinder et al, 2001). These two properties therefore tend to go hand-in-hand: both transparency and independence tend to enhance credibility (Eijffinger and Hoeberichts, 2002). Conversely, Geraats (2002b) argues that those central banks most subject to (or most concerned with) political pressures are the ones now most reluctant to be transparent about their operations.

2. An examination of the definitions of what is said to constitute an index of independence ${ }^{10}$ shows that, in practice, there is a certain overlap with what is generally regarded as transparency. Aspect $1 c$ in the E\&G index of transparency is a case in point. Here a central bank with explicit instrument independence is rewarded equally for transparency ${ }^{11}$. Moreover Geraats (2002b) reports a correlation coefficient of 0.43 between the two, using one of the standard measures of independence.

3. Much of the recent literature has argued that a conservative (inflation averse) central banker will have to put up with higher output variability if he/she is to retain lower inflation on average (Rogoff, 1985; Vredin and Warne 2000). Given a significant positive correlation between the measures of independence and transparency, that would explain our perverse result exactly. It is simply an artifact of the way this particular index of transparency has been constructed, and is not necessarily a feature of transparency in general.

4. The counterargument would be that the empirical literature has found little, if any, association between the degree of central bank independence and output volatility (Alesina and Summers, 1993). But that does not go so far as to imply a negative relationship such as we are looking for. Nor does it explain why deflation costs worsen as independence increases (Eijffinger and De Haan 1996; Ball 1999).

In short we are still left with output volatility rising when the measures of independence and transparency overlap ${ }^{12}$. Thus the upshot of our results is that

\footnotetext{
${ }^{10}$ See Eijffinger and De Haan, 1996 for a survey.

${ }^{11}$ The authors themselves argue that '....political transparency is enhanced by institutional arrangements, like central bank independence...'.

${ }^{12}$ In fact the Alesina and Summers "low inflation at no cost" result may only hold when fiscal policies are active in output stabilisation. Both Melitz (1997) and Wyploz (1999) have
} 
greater precision is really needed, first to determine what exactly this E\&G index of transparency measures; and second to design measures of transparency and independence that distinguish properly between the two. Greater modelling precision may also be needed to control for the impact of fiscal policy in reducing output variability; and for reducing the effective independence of monetary policy or the clarity of (the private sectors view of) the central banks operations.

\section{Conclusions}

A simple model of transparency in Central Bank policy making shows that increases in the degree of transparency would not affect the average levels of inflation and output achieved. But it would decrease the degree of volatility in both inflation and output gap levels - and the more so, in output volatility if the Central Bank is (weight) conservative.

When we test these predictions against the only numerical index of transparency available for nine OECD countries in the 1990s, we find that all the predictions are verified but for the reduction of output volatility. The latter appears to rise with increasing transparency. And although the size of the sample quite clearly limits our ability to draw conclusions, this result remains robust across the different sensitivity checks performed. It is likely therefore, that the transparency index captures some other elements of Central Bank behaviour - for example, differing degrees of independence or uncertainty about the policy goals that the Central Bank ought to pursue. These two are observationally equivalent in our model. This conclusion therefore, underlines our initial hypotheses: it is important to distinguish clearly between that lack of transparency which refers to the possession of precise information which the CB chooses, strategically, not to reveal to the private sector; and that lack of transparency that arises through uncertainty, meaning that the Central Bank does not have precise information itself - although it is perfectly prepared to release what information it does have. These two cases may have quite different consequences, and these empirical results suggest that what passes for a lack of transparency in conventional discussions may be as much the latter as the former.

shown that fiscal policies tend to move in opposite directions in the OECD economies - even in those with the most independent central banks. The implication is that fiscal policies have likely been used to contain output volatility, obscuring the effects of transparency or independence on inflation or output volatility. 


\section{References}

[1] Allsopp, Christopher, 2002, 'Macroeconomic Policy Rules in Theory and in Practice', paper presented in Conference on Policy Rules - The Next Steps, Clare College, Cambridge University, September 19-20.

[2] Alesina, Alberto and Lawrence Summers, 1993, 'Central Bank Independence and Macroeconomic Performance: Some Comparative Evidence', Journal of Money Credit and Banking, 25, No.2, 151-161.

[3] Aylmer, Chris, 2002, 'The Australian Experience', Workshop on Monetary Policy Rules, European Central Bank, Frankfurt, March 11-12.

[4] Ball, Lawrence, 1999, 'Aggregate Demand and Long Run Unemployment' Brookings Papers on Economic Activity 2, 189-25.

[5] Berg, Claes, Per Jansson and Anders Vredin, 2002, 'Simple Rules for Monetary Policy? Some Swedish Experiences', Workshop on Monetary Policy Rules, European Central Bank, Frankfurt, March 11-12.

[6] Blinder, Alan, 1997, 'What Central Bankers could Learn from Academics - and Vice Versa', Journal of Economic Perspectives, Volume 11, Number 2, 3-19.

[7] Blinder, Alan, 1998, Central Banking in Theory and Practice, MIT Press, Cambridge, MA.

[8] Blinder, Alan, Charles Goodhart, Philipp Hildebrand, David Lipton and Charles Wyplosz, 2001, How do Central Banks Talk?, Geneva Reports on the World Economy, 3.

[9] Bomfin, A and V Reinhart, 2000, 'Making News: Financial Market Effects of Federal Reserve Disclosure Practices', Board of Governors, Federal Reserve System, Washington, DC.

[10] Christiano, L.J. and Fitzgerald, T.J., 1999, 'The Band Pass Filter', NBER Working Paper Series, No. 7257.

[11] Cukierman, Alex, 1992, Central Bank Strategy, Credibility and Independence: Theory and Evidence, MIT Press, Cambridge, MA.

[12] Cukierman, Alex, 2000, 'Accountability, Credibility, Transparency and Stabilisation Policy in the Euro System', Tel-Aviv University, Israel.

[13] Cukierman, Alex and A. Meltzer, 1986, 'A Theory of Ambiguity, Credibility and Inflation under Discretion and Asymmetric Information' Econometrica, 54, 1099-1128.

[14] Eijffinger, Sylvester Jakob de Haan, 1996, 'The Political Economy of Central-Bank Independence', Special Papers in International Economics, No. 19, Princeton University, May. 
[15] Eijffinger, Sylvester and Marco Hoeberichts, 2002, 'Central Bank Accountability and Transparency: Theory and some Evidence', International Finance, 5:1, 73-96.

[16] Eijffinger, Sylvester and Petra Geraats, 2002, 'How Transparent are Central Banks?', Centre for Economic Policy Research, London, Discussion Paper, No. 3188, February.

[17] Faust, Jon and Lars Svensson, 2001, 'Transparency and Credibility: Monetary Policy with Unobservable Goals', International Economic Review, 42, 369-07.

[18] Faust, Jon and Lars Svensson, 2002, 'The Equilibrium Degree of Transparency and Control in Monetary Policy', Journal of Money, Credit and Banking, Vol. 34, No. 2, 520-539.

[19] Friedman, Benjamin, 1997, 'The Rise and Fall of Monetary Targets in US Monetary Policy', in I. Kirode (ed), Towards a More Effective Monetary Policy, St. Martins Press, New York.

[20] Geraats, Petra, 2002, 'Central Bank Transparency', The Economic Journal, 112, November, F532-F565.

[21] Geraats, Petra, 2002b, 'Transparency of Monetary Policy: Does the Institutional Framework Matter?', Mimeo, University of Cambridge, July.

[22] Hodrick, R.J and Prescott, E.C., 1997, 'Post-War U.S. Business Cycles: A descriptive Empirical Investigation', Journal of Money Credit and Banking, No. 29, 1-16.

[23] Hughes Hallett, Andrew and Nicola Viegi, 2001, 'Transparency and the Strategic Use of Private Information in Monetary Policy', Centre for Economic Policy Research, London, Discussion Paper, No. 2671.

[24] Issing, Otmar, 1999, 'The Eurosystem: Transparent and Accountable', Journal of Common Market Studies, 37, 503-20.

[25] Jensen, Henrik, 2000, 'Optimal Degrees of Transparency in Monetary Policy Making', University of Copenhagen, September.

[26] Jordan, Thomas J and Michel Peytrignet, 2002, 'Inflation Forecasting at the Swiss National Bank', Workshop on Monetary Policy Rules, European Central Bank, Frankfurt,March 11-12.

[27] Kuttner, Kenneth and Adam Posen, 1999, 'Does Talk Matter After All? Inflation Targeting and Central Bank Behaviour', Report 88, Reserve Bank of New York.

[28] Kuttner, Kenneth and Adam Posen, 2000, 'Inflation, Monetary Transparency and G3 Exchange Rate Volatility', Report 00-6, Institute for International Economics, Washington DC. 
[29] Nolan, Charles and Eric Schaling, 1998, 'Monetary Policy Under Uncertainty and Central Bank Accountability', De Economist, 146, 585-602.

[30] Melitz, Jacques, 1997, 'Some Cross Country Evidence about Debt, Deficits and the Behaviour of Monetary and Fiscal Authorities', Centre for Economic Policy Research, London, Discussion Paper, No. 1653.

[31] Muscatelli, Anton, 1998, 'Optimal Inflation Contacts and Inflation Targets with Uncertain Central Bank Preferences: Accountability through Independence?', Economic Journal, 108, 529-42.

[32] Rogoff, Kenneth, 1985, 'The Optimal Degree of Commitment to a Monetary Target', Quarterly Journal of Economics, 100, No. 4, 1169-90.

[33] Sibert, Anne, 2002, 'Monetary Policy with Uncertain Central Bank Preferences', European Economic Review, 46, 1093-1109.

[34] Vredin Anders and Anders Warne, 2000, 'Unemployment and Inflation Regimes', Working Paper Series, Sveriges Riksbank, No 107, May.

[35] Wyploz, Charles, 1999, 'Economic Policy Coordination in EMU: Strategies and Institutions', ZEI Policy Paper B11, University of Bonn. 


\section{APPENDICES}

\section{A Imperfect Political Transparency: An Uncer- tain value for parameter $b$}

The CB optimises the following:

$$
\min _{\pi} L=\frac{1}{2} E\left[\pi^{2}+b(\pi-\beta k+\varepsilon-k)^{2}\right]
$$

such that

$$
\frac{\partial L}{\partial \pi}=\pi+b(\pi-\beta k+\varepsilon-k)=0
$$

and hence

$$
\pi^{*}=\frac{b(1+\beta) k}{1+b}-\frac{b}{1+b} \varepsilon
$$

Note that $E\left(\pi^{*}\right)=b k=E\left(\pi^{e}\right)$. We calculate the variance of inflation as follows:

$$
\begin{aligned}
\pi^{*}-E\left(\pi^{*}\right) & =\frac{b(1+\beta) k}{1+b}-\frac{b}{1+b} \varepsilon-b k \\
& =\frac{b}{1+b}(\eta k-\varepsilon)
\end{aligned}
$$

And since $V\left(\pi^{*}\right)=E\left[\pi^{*}-E\left(\pi^{*}\right)\right]^{2}$, we have

$$
V\left(\pi^{*}\right)=\left(\frac{b}{1+b}\right)^{2}\left(k^{2} \sigma_{\eta}^{2}+\sigma_{\varepsilon}^{2}\right)
$$

assuming that $E(\eta, \varepsilon)=0$.

The level of output achieved in equilibrium is now

$$
\begin{aligned}
y^{*} & =\frac{b(1+\beta) k}{1+b}-\frac{b}{1+b} \varepsilon-\beta k+\varepsilon \\
& =\frac{\varepsilon-\eta k}{1+b}
\end{aligned}
$$

But this implies that $E\left(y^{*}\right)=0$ and $V\left(y^{*}\right)=E(y)^{2}$ or

$$
V\left(y^{*}\right)=\frac{\sigma_{\varepsilon}^{2}+k^{2} \sigma_{\eta}^{2}}{(1+b)^{2}}
$$




\section{A.1 Imperfect Economic Transparency: An Uncertain value for parameter $k$}

As the CB optimises:

$$
\min _{\pi} L=\frac{1}{2} E\left[\pi^{2}+b(\pi-b c+\varepsilon-k)^{2}\right]
$$

Solving this for $\pi^{*}$ produces:

$$
\begin{aligned}
\frac{\partial L}{\partial \pi} & =\pi+b(\pi-b c+\varepsilon-k)=0 \\
\pi^{*} & =\frac{b(b c+k)}{1+b}-\frac{b}{1+b} \varepsilon
\end{aligned}
$$

And hence $E\left(\pi^{*}\right)=b k$. The variance is calculated as follows $V\left(\pi^{*}\right)=E\left[\pi^{*}-E\left(\pi^{*}\right)\right]^{2}$. First, we calculate deviations from mean:

$$
\begin{aligned}
\pi^{*}-E\left(\pi^{*}\right) & =\frac{b}{1+b}[b c+k-\varepsilon]-b k \\
& =\frac{b}{1+b}(b v-\varepsilon)
\end{aligned}
$$

and actual variance:

$$
V\left(\pi^{*}\right)=\left(\frac{b}{1+b}\right)^{2}\left(b^{2} \sigma_{v}^{2}+\sigma_{\varepsilon}^{2}\right)
$$

Similarly for output. The public forms expectations for inflation as $\pi^{e}=b c$. In equilibrium therefore, output is equal to the following.

$$
\begin{aligned}
y^{*} & =\frac{b(b c+k)}{1+b}-\frac{b \varepsilon}{1+b}-b c+\varepsilon \\
& =\frac{\varepsilon-b v}{1+b}
\end{aligned}
$$

It is easy to see that $E\left(y^{*}\right)=0$. The variability of output in equilibrium is therefore given by:

$$
V\left(y^{*}\right)=\frac{\sigma_{\varepsilon}^{2}+b^{2} \sigma_{v}^{2}}{(1+b)^{2}}
$$

assuming $\varepsilon$ and $v$ are uncorrelated. 


\section{B Data}

We examine the countries included in the E\&G index, namely, New Zealand, UK, Sweden, Canada, the Euro area, US, Australia, Japan and Switzerland. We use the following quarterly series: CPI inflation (year on year), real GDP (volumes deflated by GDP deflators) deviations from trend (calculated by the Hodrick-Prescott and the Cristiano-Fitzgerald filters). The data range from the early 90 s till the end of 2001 for most countries and are taken from Datastream and the ECB. As explained in the main text, the index of transparency reflects an institutional set up that varies from country to country. To allow for this therefore, the macroeconomic variables are only considered for the relevant years for each of the countries, based on information available to us. The adjustments made therefore, are as follows:

- Sweden: we consider data from 1993 onwards since this is the first phase associated with the Riksbank gaining credibility (Berg et al 2002).

- Australia: we consider data from 1996, the time the inflation target was formally enshrined in the Statement on the Conduct of Monetary Policy. (Aylmer, 2002)

- Switzerland: there has been a new monetary policy concept since the beginning of 2000 in Switzerland but this is too recent to allow for any variance in inflation (Jordan and Peytrignet, 2002). We consider data for the whole period therefore.

- UK: we consider the time period from 1998, since the Bank of England was given operational independence only in May 1997 (see Allsopp,2002).

- Despite the late creation of EMU (1999) we consider data from the start of the $90 \mathrm{~s}$ on the basis that convergence was necessary before the actual creation of a centralised monetary authority in Europe. We have experimented however, with shorter periods starting towards the end of the $90 \mathrm{~s}$ but the results derived were very similar.

For the remainder of the countries we consider the period from the start of the 90s.

\section{B.1 Sensitivity Analysis}

The figures included in the main text calculate the mean and standard deviations of the two variables over the implied periods and then correlate them to the aggregate and component indices of transparency constructed by Eijffinger and Geraats (2002), or with our regrouped indices for political and economic transparency. In what follows we present some comments on the sensitivity of the results. We conduct a number of sensitivity tests. 
- Comments on outliers. Figures 7 and 8 drop Japan and Switzerland respectively and examine what happens to the relevance of the E\&G index as a result. These figures are comparable to the first plots of overall transparency, i.e. figures 1(a)-4(a). The results remain very similar to what is attained with the two countries included; the variance of inflation is the main variable that is affected by transparency and the variance of output appears to deteriorate as transparency increases. The significance of these results is slightly weakened by dropping these two countries.

- Changing the Sample Size. An extra source of sensitivity naturally arises from the sample period chosen, for which to calculate the average and standard deviations. In the case of the UK this turns out to be particularly important. We present therefore, the impact implied on the whole index when the average and standard deviation of inflation and output considered for the UK are calculated for the whole of the 90s and not starting from 1998. (Figure 9). We compare those again to figures 1(a)-4(a). The results are now different to what we got before, in that any significance in the results is lost and the relationship between average inflation and transparency is positive (although insignificant). As already mentioned, this did not make much of a difference in the case of the Euro area. Nevertheless, this points to the fact that identifying the correct sample (in the sense that it matches the institutional set-up described by the index) may be empirically important.

- Deriving the Output Deviation from Trend. Finally we apply two standard methodologies to derive potential output, namely the HodrickPrescott, 1997 (HP) and the Christiano Fitzgerald 1999 (CF) filters. The results obtained using the former are given in the main text. Figures 1012 present the results obtained when using the CF filter and are directly comparable to figures 3,4 and 6 respectively. We apply these two filters because they make use of two alternative methodologies for extracting trends. The former relies thus on a smoothing parameter which encapsulates the trade-off between having to reduce the variability of the derived series on the one hand and wanting to stick as close to the original data as possible, on the other. The CF filter is part of a more recently developed literature and falls in the category of band-pass filters. These types of filters focus on a predetermined frequency range which has a clearer interpretation. However, it is a relatively new filter which has not been widely tested empirically. We will therefore only use it as a yardstick for comparison. The comparisons are quite similar to ones previous made. The variance of the output gap is positively correlated with transparency and with very similar levels of significance. The level of the output gap however, is now related negatively to transparency and is more stronger than before. It remains insignificant however at the confidence levels considered.

- A case for omitted variables. Given the limitations of the data set, 
the regressions performed can only be seen as an attempt to identify correlations rather than strong causal relationships between the variables examined. We acknowledge the fact that regressions of this sort will suffer from omitted-variables effects, reflecting the possible influences of macroeconomic variables (like fiscal policy stance, openness to trade) or possible correlations between the variability of inflation and output. We have experimented with respect to the latter, therefore including the variability of output as a regressor in the variability of inflation equation, and the other way round. The results obtained however, (available from the authors) are very similar to the ones presented.

- Alternative groupings. Naturally, there is no clear-cut way of grouping the sub-components of the E\&G index. In the main text we have identified Political Transparency with the sum of 1a, 1c, 3a, 3b, 3c, 4a, 4b and 4c and Economic Transparency with the sum of 1b, 2a, 2b, 2c, 5a, 5b, 5c and $1 \mathrm{~b}$. As an alternative grouping we have experimented with incorporating Policy transparency (4a, 4b and 4c) as part of the Economic grouping. The results (available by the authors) are very similar to ones already described (albeit political transparency is less significant). 
Figure 1 Average Inflation and Transparency

(y-axis: Average Inflation)

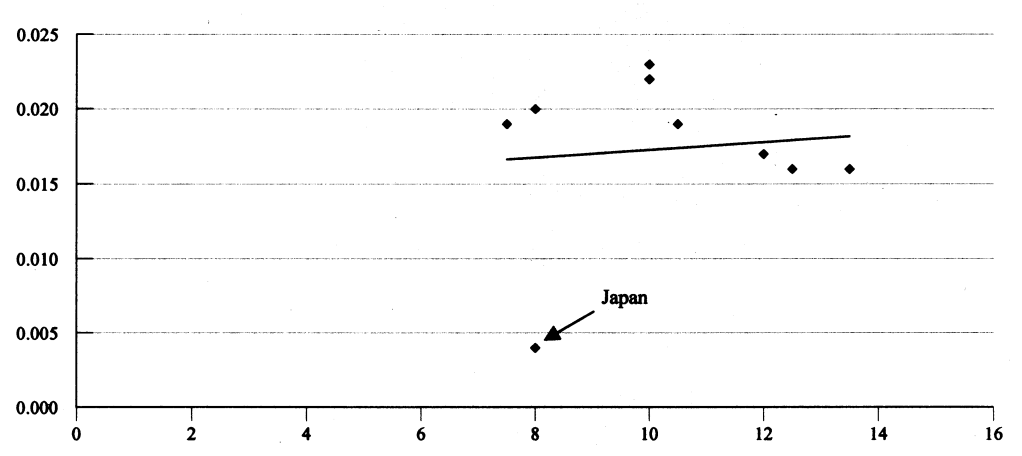

(a) Index of Total Transparency

$R^{2}=0.0104 \quad t=0.27$

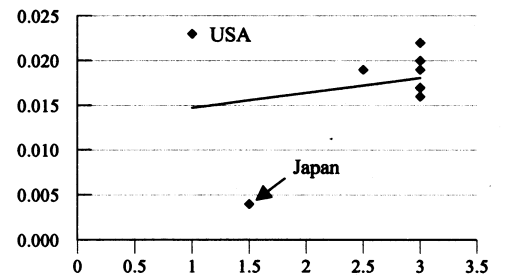

(b) Index of Political Transparency

$$
R^{2}=0.0567 \quad t=0.64
$$

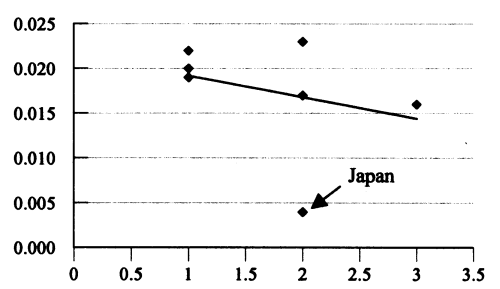

(d) Index of Procedural Transparency

$$
\mathrm{R}^{2}=0.1327
$$

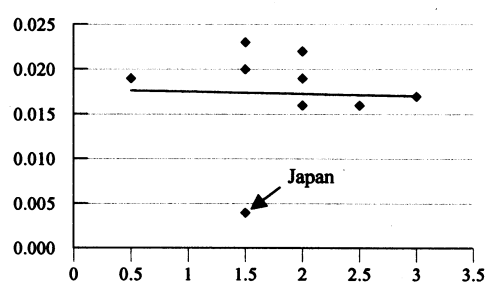

(f) Index of Operational Transparency

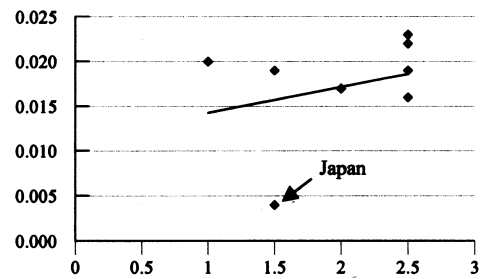

(c) Index of Economic Transparency

$$
R^{2}=0.0835 \quad t=0.79
$$

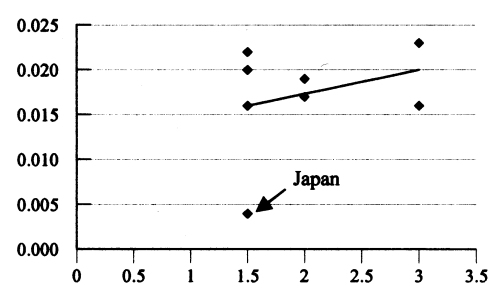

(e) Index of Policy Transparency

$$
R^{2}=0.0891 \quad t=0.82
$$

critical value: $\mathrm{t}_{(8) 95 \%}=2.3$

critical value: $\mathrm{t}_{(8) 90 \%}=1.8$

Figure 1: 
Figure 2 Variance of Inflation and Transparency

(y-axis: Variance of Inflation)

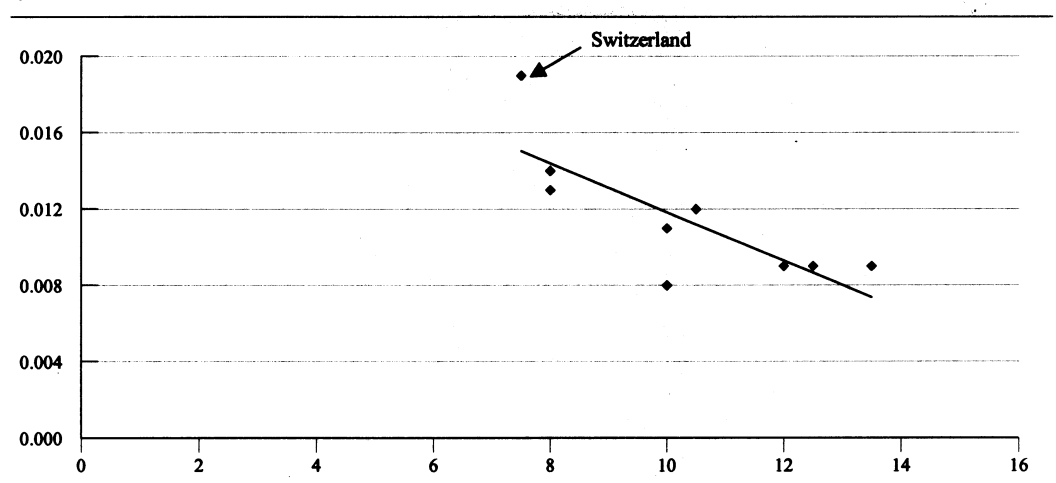

(a) Index of Total Transparency

$R^{2}=\mathbf{0 . 5 7 2 8} \quad t=-3.06$

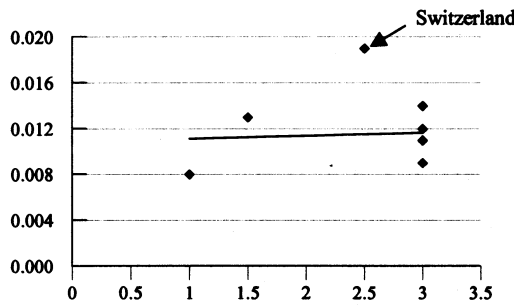

(b) Index of Political Transparency

$\mathrm{R}^{2}=0.0097 \quad \mathrm{t}=0.26$

Switzerland

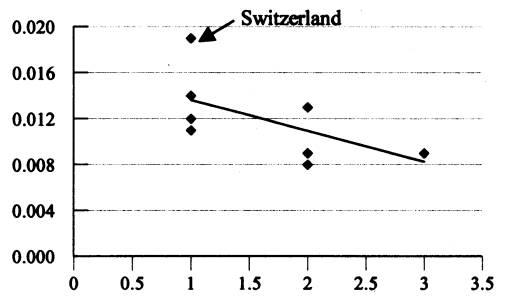

(d) Index of Procedural Transparency

$R^{2}=0.3964 \quad t=-2.14$

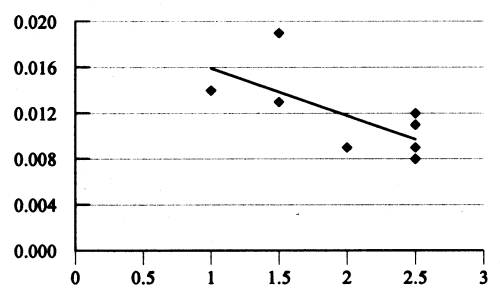

(c) Index of Economic Transparency

$R^{2}=0.4836 \quad t=-2.56$

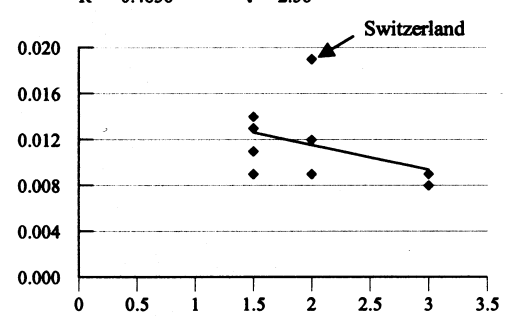

(e) Index of Policy Transparency

$R^{2}=0.1338 \quad t=-1.03$

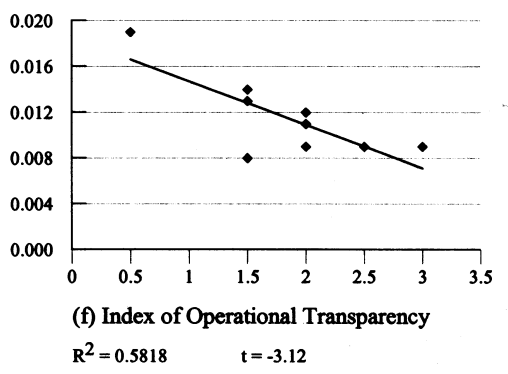

critical value: $\mathrm{t}_{(8) 95 \%}=2.3$

critical value: $\mathrm{t}_{(8)} 90 \%=1.8$

Figure 2: 
Figure 3 Average Output Deviations and Transparency HP (y-axis: Average Output)

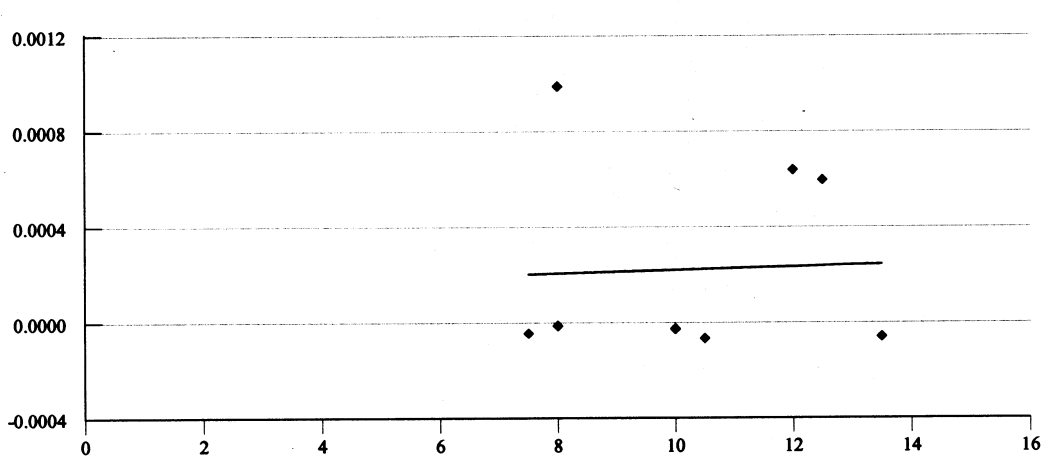

(a) Index of Total Transparency

$R^{2}=0.0013 \quad t=0.09$
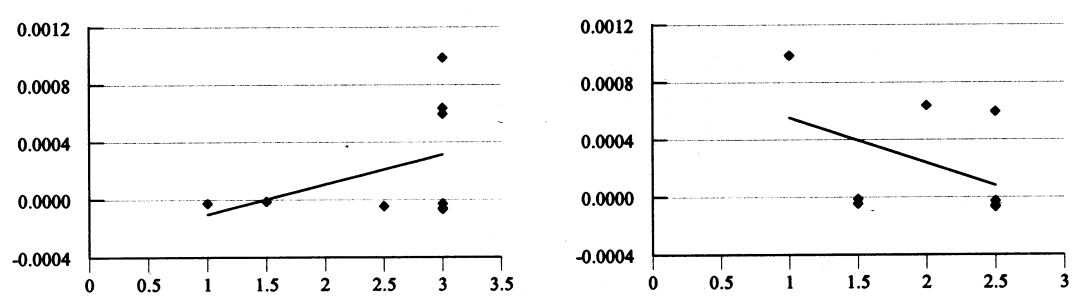

(b) Index of Political Transparency

$R^{2}=0.1538 \quad t=1.12$

(c) Index of Economic Transparency

$R^{2}=0.2073 \quad t=-1.35$
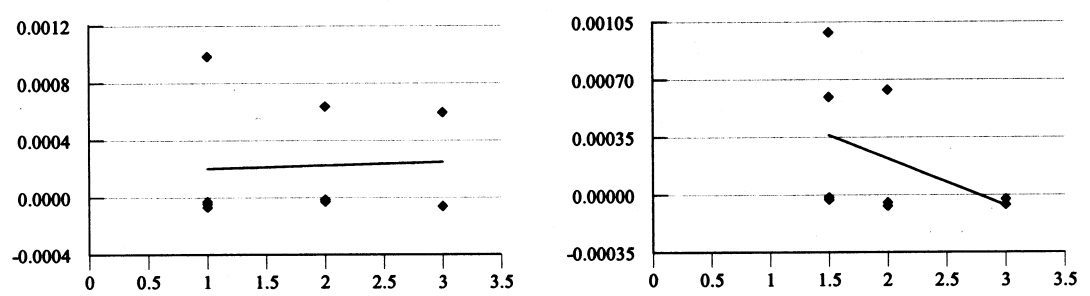

(d) Index of Procedural Transparency

$R^{2}=0.0023 \quad t=0.12$

(e) Index of Policy Transparency

$R^{2}=0.1863$

$t=-1.27$

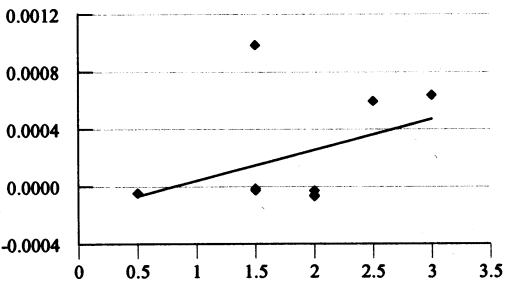

critical value: $\mathrm{t}_{(8) 95 \%}=2.3$

critical value: $\mathrm{t}_{(8)} 90 \%=1.8$

(f) Index of Operational Transparency

$R^{2}=0.141$

$\mathbf{t}=\mathbf{1 . 0 7}$

Figure 3: 
Figure 4 Variance of Output Deviations and Transparency HP (y-axis: Variance Output)

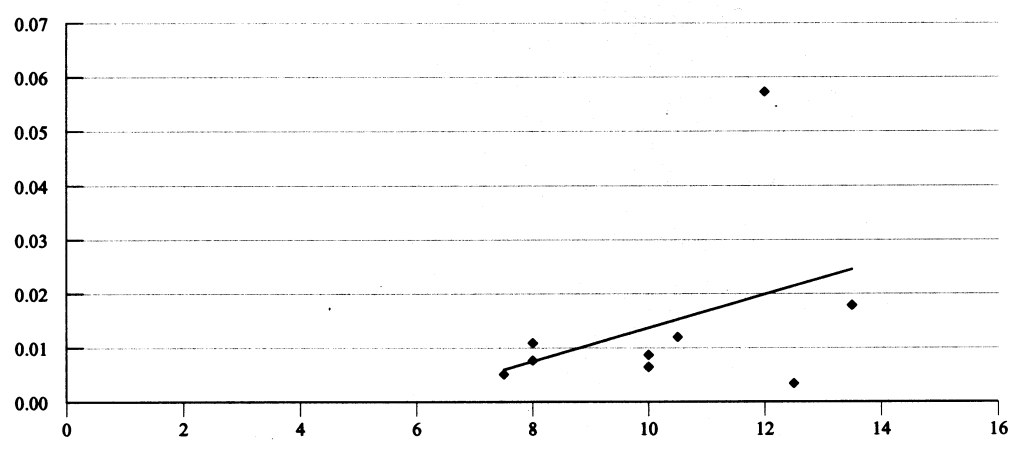

(a) Index of Total Transparency

$R^{2}=0.1573 \quad t=1.14$
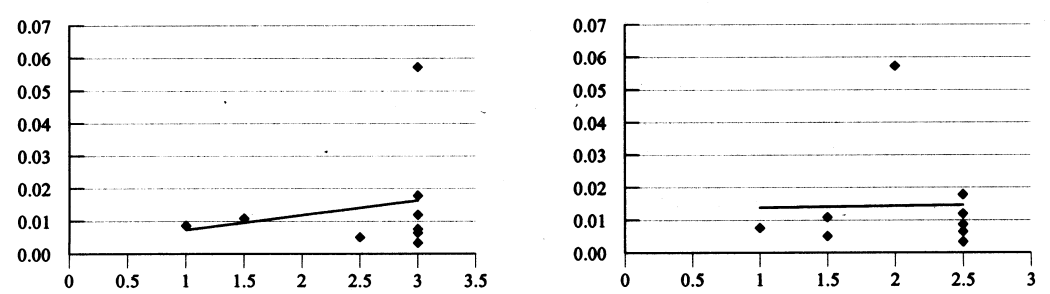

(b) Index of Political Transparency

(c) Index of Economic Transparency

$R^{2}=0.0429 \quad t=0.56$

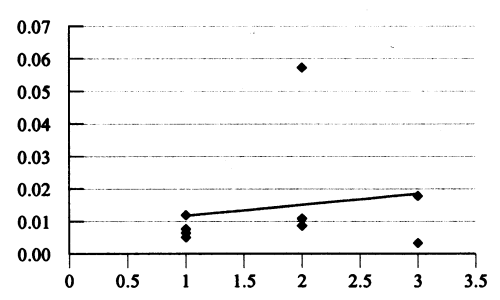

(d) Index of Procedural Transparency

$R^{2}=0.0287$

$t=0.45$

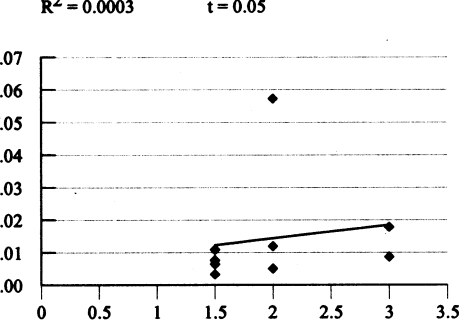

(e) Index of Policy Transparency

$R^{2}=0.0229$

$t=0.40$

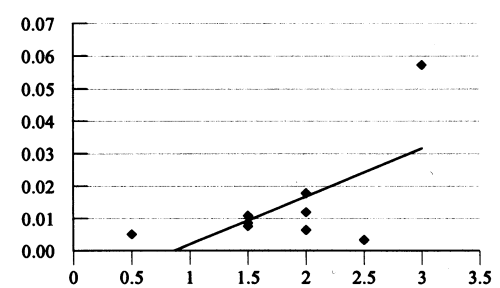

critical value: $\mathrm{t}_{(8) 95 \%}=2.3$

critical value: $\mathrm{t}_{(8)} 90 \%=1.8$

(f) Index of Operational Transparency

$R^{2}=0.3958 \quad t=2.14$

Figure 4: 
Figure 5 Alternative Definition of Transparency

\section{Inflation and Political Transparency}

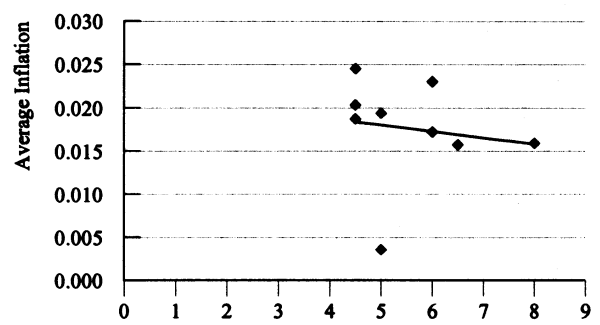

(a) Index of Political Transparency

$R^{2}=0.0207 \quad t=-0.38$

Inflation and Economic Transparency

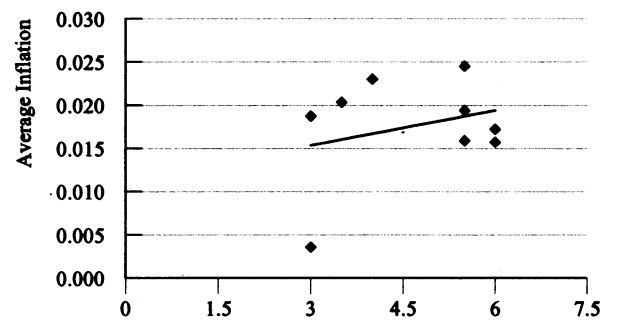

(c) Index of Economic Transparency

$R^{2}=0.0808 \quad t=0.78$

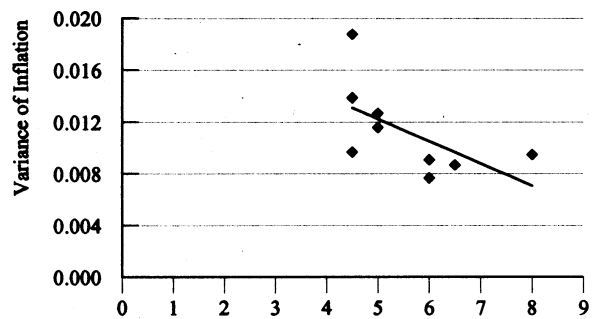

(b) Index of Political Transparency

$R^{2}=0.3481 \quad t=-1.93$

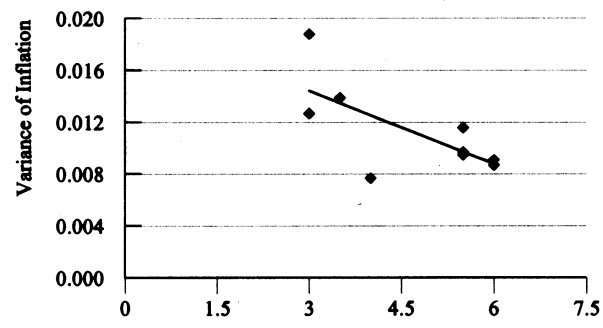

(d) Index of Economic Transparency

$R^{2}=0.4804 \quad t=-2.5$

\footnotetext{
Variance $=S D \quad$ critical value: $t_{(8) ~ 95 \%}=2.3$ critical value: $t_{(8)} 90 \%=1.8$
}

Figure 5: 
Figure 6 Alternative Definition of Transparency

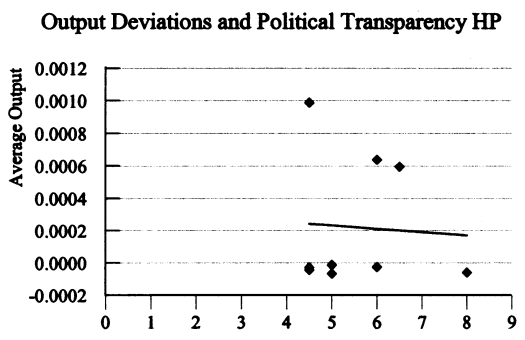

(a) Index of Political Transparency

$R^{2}=0.0036$

$t=-0.16$

Output Deviations and Economic Transparency HP

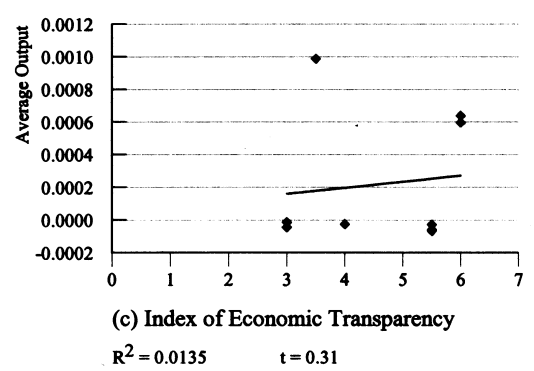

(c) Index of Economic Transparency

$R^{2}=0.0135 \quad t=0.31$

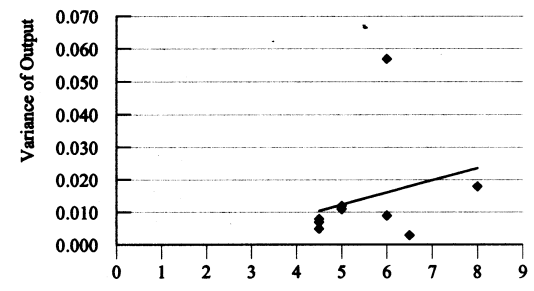

(b) Index of Political Transparency

$R^{2}=0.0749$

$t=0.75$

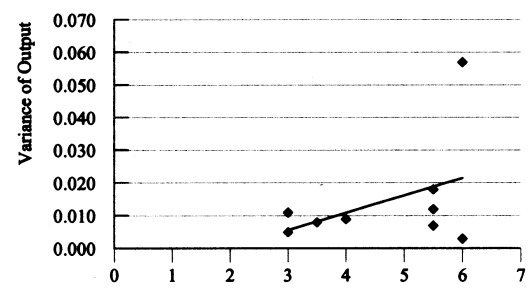

(d) Index of Economic Transparency $\mathrm{R}^{2}=\mathbf{0 . 1 6 8 8}$

Variance $=\mathrm{SD} \quad$ critical value: $\mathrm{t}_{(8)} 95 \%=2.3$ critical value: $\mathrm{t}_{(8) 90 \%}=1.8$

Figure 6: 


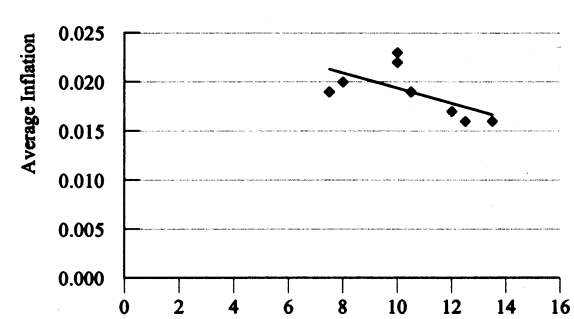

(a) Index of Total Transparency

$R^{2}=0.3963$

$t=-1.98$

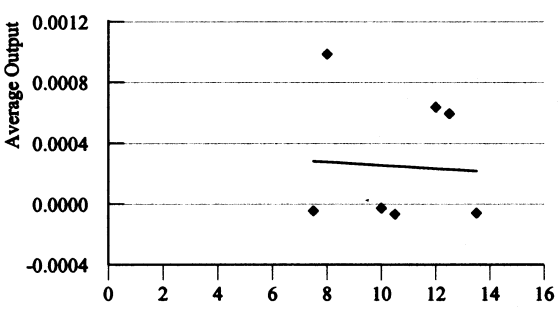

(c) Index of Total Transparency

$R^{2}=0.0029 \quad t=-0.13$

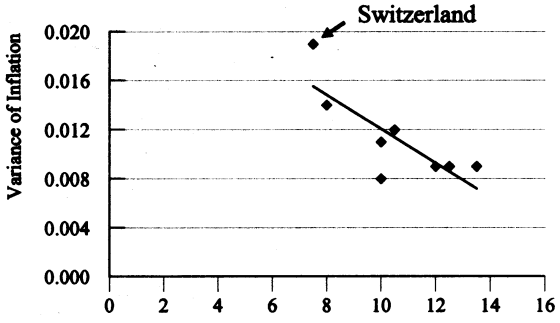

(b) Index of Total Transparency

$R^{2}=0.5956$

$t=-2.97$

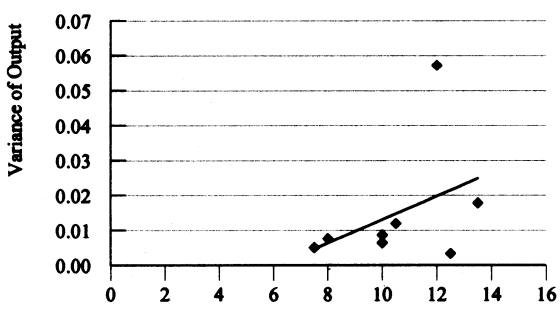

(d) Index of Total Transparency

$R^{2}=0.159 \quad t=1.065$

critical value: $t_{(7)} 95 \%=2.36$

critical value: $t_{(7)} 90 \%=1.89$

Figure 7: 


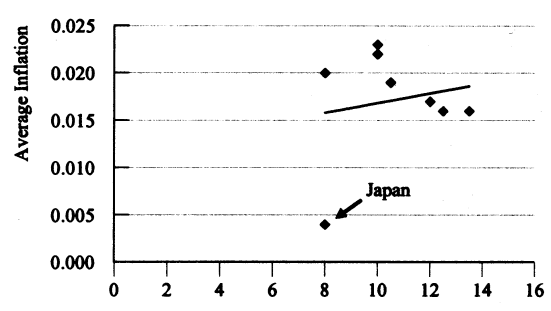

(a) Index of Total Transparency $\mathrm{R}^{2}=0.0286$

$t=0.42$

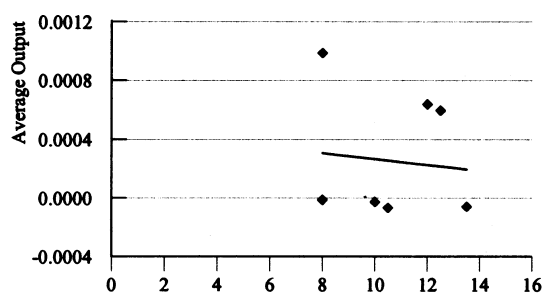

(c) Index of Total Transparency $R^{2}=0.0091$

$$
t=-0.23
$$

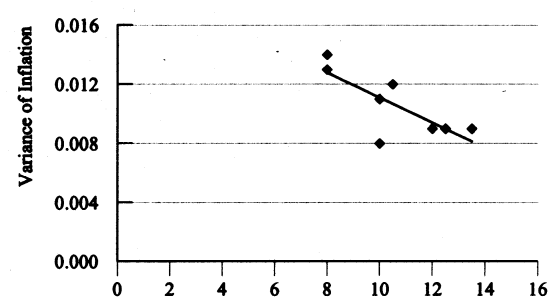

(b) Index of Total Transparency $R^{2}=0.5151$

$\mathbf{t}=-2.5$

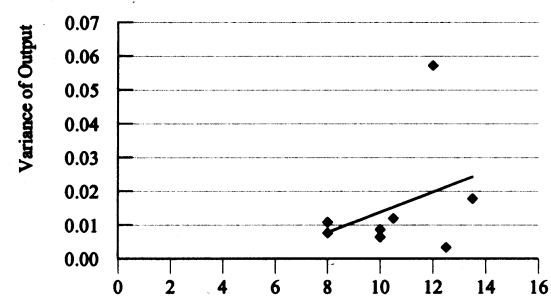

(d) Index of Total Transparency $R^{2}=0.1195$ $t=0.90$

critical value: $t_{(7) 95 \%}=2.36$ critical value: $t_{(7)} 90 \%=1.89$

Figure 8: 
Figure 9 The Index with a different period for the UK

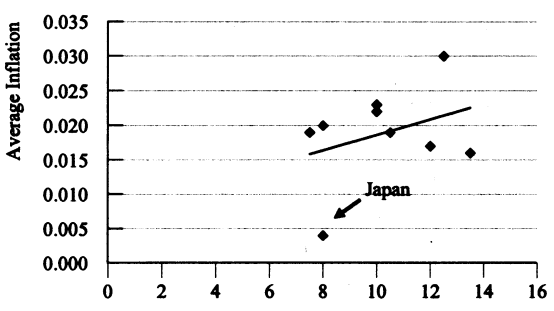

(a) Index of Total Transparency

$$
\mathrm{R}^{2}=\mathbf{0 . 1 2 5 9} \mathrm{t}=\mathbf{1 . 0 0 4}
$$

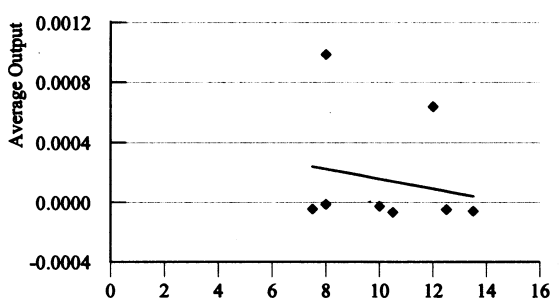

(c) Index of Total Transparency

$R^{2}=0.0339 \quad t=-0.49$

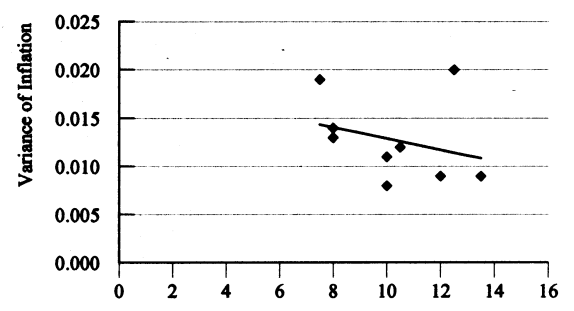

(b) Index of Total Transparency

$R^{2}=0.0658 \quad t=-0.7$

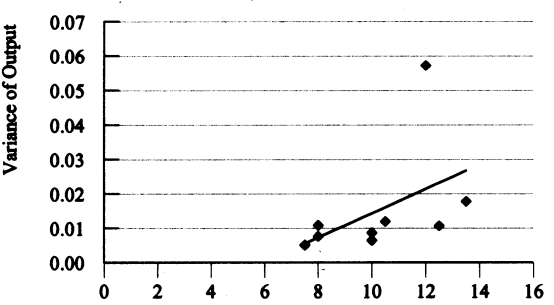

(d) Index of Total Transparency

$R^{2}=0.2181 \quad t=1.39$

critical value: $\mathrm{t}_{(8) 95 \%}=\mathbf{2 . 3}$

critical value: $t_{(8) 90 \%}=1.8$

Figure 9: 
Figure 10 Average Output Deviations and Transparency CF (y-axis: Average Output)

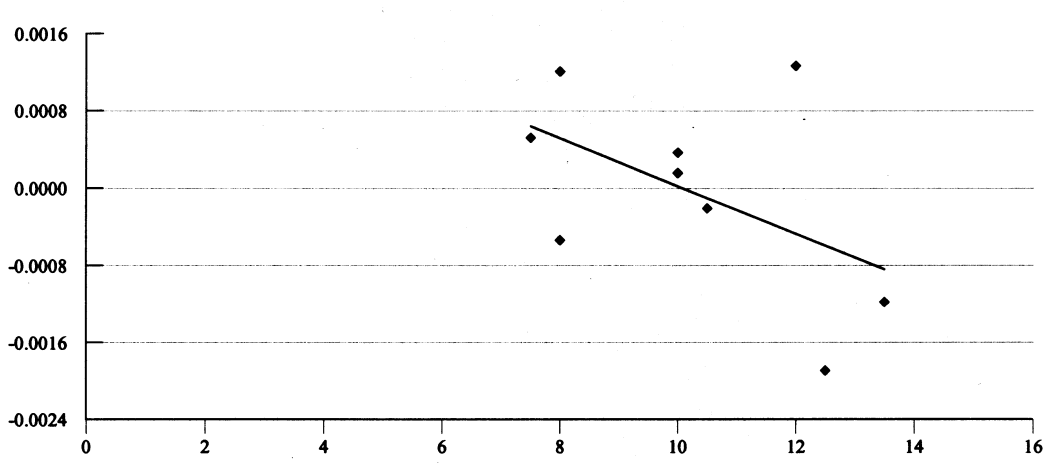

(a) Index of Total Transparency

$$
R^{2}=0.2527 \quad t=-1.53
$$

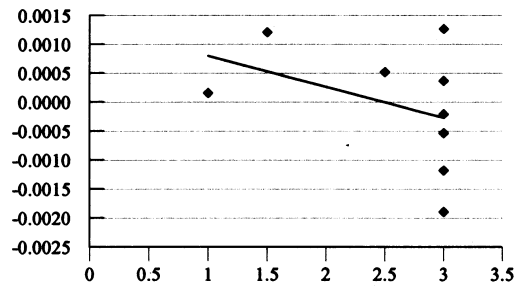

(b) Index of Political Transparency

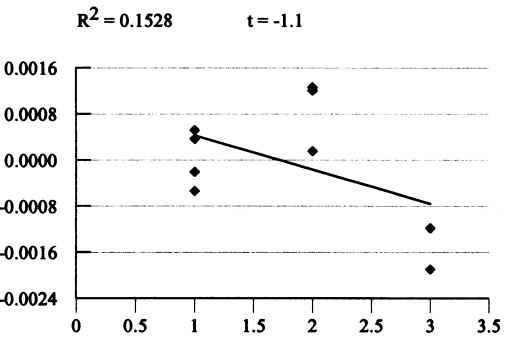

(d) Index of Procedural Transparency

$R^{2}=0.221$

$t=-1.40$

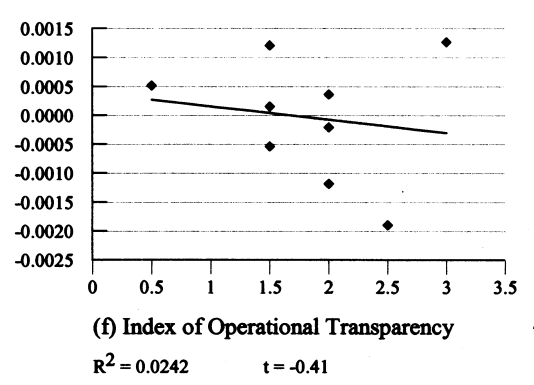

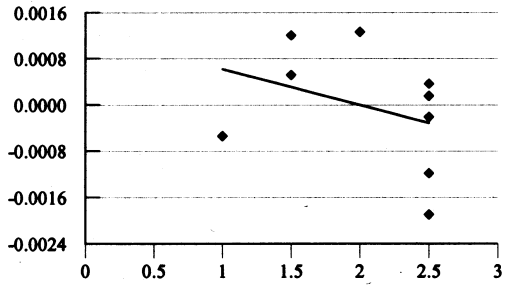

(c) Index of Economic Transparency $R^{2}=0.119 \quad t=-0.97$

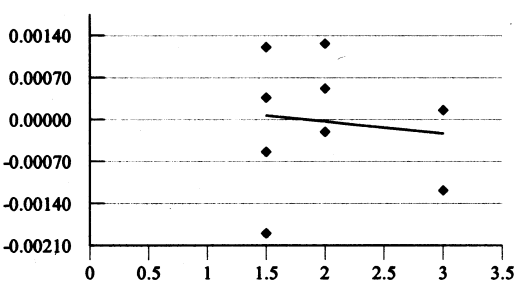

(e) Index of Policy Transparency $R^{2}=0.0135 \quad t=-0.31$

critical value: $\mathrm{t}_{(8)} 95 \%=2.3$ critical value: $\mathrm{t}_{(8)} 90 \%=1.8$

Figure 10: 
Figure 11 Variance of Output Deviations and Transparency CF

(y-axis: Variance of Output)

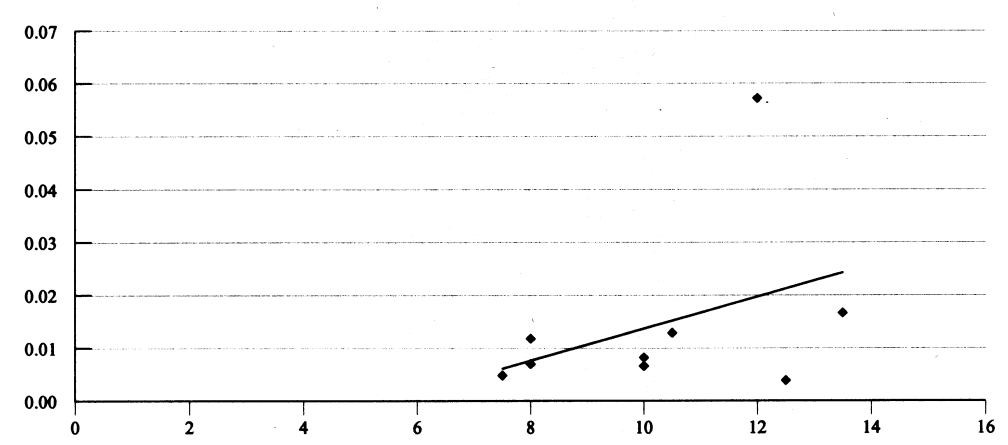

(a) Index of Total Transparency

$\mathrm{R}^{2}=\mathbf{0 . 1 5 1 3} \quad \mathrm{t}=1.1$

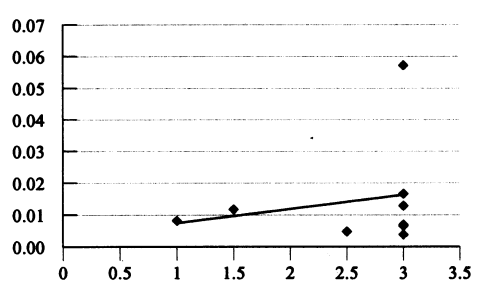

(b) Index of Political Transparency

$R^{2}=0.0416$

$t=0.55$

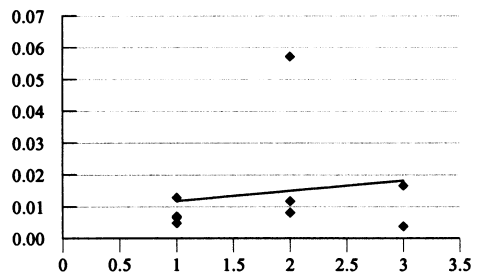

(d) Index of Procedural Transparency

$R^{2}=0.026 \quad t=0.43$

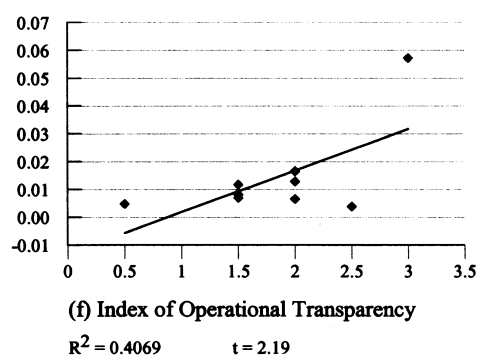

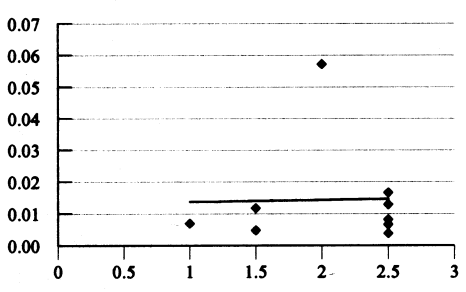

(c) Index of Economic Transparency

$\mathrm{R}^{2}=\mathbf{0 . 0 0 0 4} \mathrm{t}=\mathbf{0 . 0 6}$

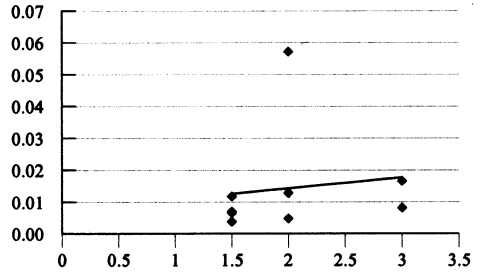

(e) Index of Policy Transparency

$R^{2}=0.0158 \quad t=0.33$

critical value: $\mathrm{t}_{(8)} 95 \%=2.3$

critical value: $\mathrm{t}_{(8)} 90 \%=1.8$

Figure 11: 
Figure 12 Alternative Definition of Transparency (CF-filter)

Output Deviations and Political Transparency CF

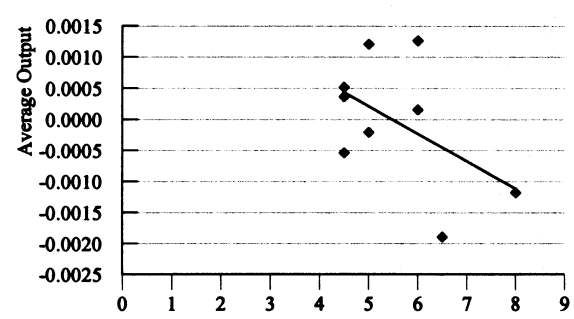

(a) Index of Political Transparency

$R^{2}=0.2503 \quad t=-1.53$

Output Deviations and Economic Transparency CF

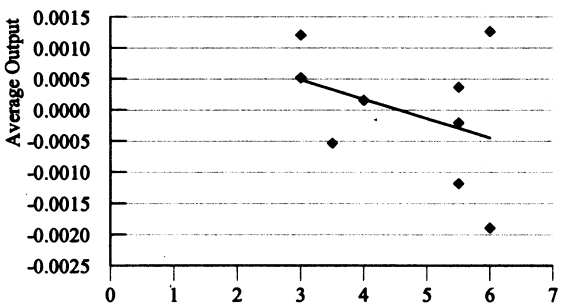

(c) Index of Economic Transparency

$R^{2}=0.1429$

$t=-1.1$

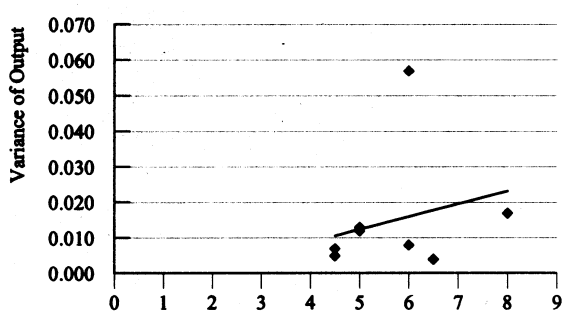

(b) Index of Political Transparency

$R^{2}=0.0654$

$t=0.7$

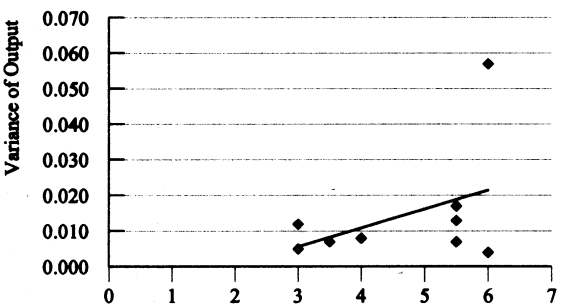

(d) Index of Economic Transparency

$R^{2}=0.1718$

$t=1.21$

Variance $=S$ critical value: $t_{(8)} 95 \%=2.3$

critical value: $t_{(8) 90 \%}=1.8$

Figure 12: 